\title{
Correction to: Source apportionment of heavy metal with UNMIX in ambient air of Ahvaz City, Southwest of Iran
}

\author{
R. Alidadi ${ }^{1}$ (1) N. Mansouri ${ }^{1}$ - A. H. Hemmasi ${ }^{1}$ - S. A. Mirzahosseini ${ }^{1}$
}

Published online: 7 May 2021

(c) Islamic Azad University (IAU) 2021

\section{Correction to: International Journal of Environmental Science and Technology https://doi.org/10.1007/s13762-021-03206-4}

The authors would like to inform readers that the correct spelling of the third author name is "A. H. Hemmasi".

The authors would like to apologize for any inconvenience caused.

The original article has been corrected.

The original article can be found online at https://doi.org/10.1007/ s13762-021-03206-4.

R. Alidadi

alidadi161@gmail.com

1 Environmental Engineering Department, Science and Research Branch, Islamic Azad University, Tehran, Iran 